\title{
Simulation of Recovery of Aroma Compound from Aqueous Solutions by Batch Pervaporation Coupled with Permeate Decantation and Water Phase Recycle
}

\author{
Muhammad Mujiburohman ${ }^{1, *}$ and Xianshe Feng ${ }^{2}$ \\ ${ }^{1}$ Department of Chemical Engineering, Universitas Muhammadiyah Surakarta, Surakarta 57102, Indonesia \\ ${ }^{2}$ Department of Chemical Engineering, University of Waterloo, Waterloo, ON N2L 3G1, Canada
}

\begin{abstract}
In this work, the dynamic (batch) models of recovery of low soluble aroma compounds from aqueous solutions by pervaporation coupled with permeate decantation and water phase recycle was derived and simulated. The model was run to simulate the pervaporation of propyl propionate-water separation using PEBA membrane. The effect of two parametric models (i.e. ratio of feed mass over membrane area $\left(F_{0} / A_{m}\right)$ and the aroma solubility in water) on the aroma compound recovery was studied. As compared to the conventional pervaporation, the application of water phase recycle was known to be able to enhance the recovery of aroma compounds in various extents, depending on the operating time and aroma solubility. The larger membrane area used (or smaller $\left(F_{o} / A_{m}\right)$ ) did not affect the maximum aroma compound recovery, but only shortened the operating time. For the aroma solubility of $0.56,1$, and $5 \mathrm{wt} . \%$, referring to the optimum operating time in the conventional mode, the extent of improvement in recovery can be around 7,10 and $16 \%$, respectively. The modified pervaporation process also offered another advantage that the process would not be strictly restricted by the operating time due to permanent increase in cumulative mass of aroma compound recovered in the product.
\end{abstract}

Keywords: Dynamic model, aroma compound recovery, pervaporation, permeate decantation, water phase recycle.

\section{INTRODUCTION}

Pervaporation (PV) has been well established for dehydration of alcohols (mainly ethanol and isopropanol) and removal of volatile organic compounds from contaminated water in wastewater treatment [1]. Using appropriate membrane materials, $\mathrm{PV}$ is also potential for ethanol recovery from aqueous solutions [2], which is a reverse process of ethanol dehydration, separation of organic/organic mixtures [3, 4], as well as the recovery of natural aroma compounds (particularly high-value aroma compounds) from aqueous solutions [5-14].

In particular to aroma compound recovery, the abundant and sustainable sources, large market demand, and the high market prices of natural aroma compounds are apparently some of the driving factors to extend the industrial application of PV. Not few studies have reported that using selective membranes (i.e. organophilic), PV was able to concentrate the aroma compounds at a high separation factor [5-14]. In case of recovery of low solubility aroma compounds, the permeate concentration attained can exceed the solubility limit and thus a phase separation takes place in the permeate stream, resulting in two phases: an

\footnotetext{
*Address correspondence to this author at the Department of Chemical Engineering, Universitas Muhammadiyah Surakarta, Surakarta 57102, Indonesia; E-mail: mmujiburohman@ums.ac.id
}

organic phase and a water phase. In order to enhance the recovery of aroma compound where a phase separation takes place in the permeate collector, the recycle of the aroma compound from the water phase is considered important. This modified PV process consists of two streams recycled into the feed tank i.e. one is the retentate stream from the membrane chamber like in a conventional PV system, and the other is the water phase from the permeate decanter, as shown in Figure 1. Such a process design has been proposed previously in our lab [15], but no extensive study has been done yet to verify this modified PV process.

Different process designs have also been proposed and simulated by others including: aroma compound recovery using solvent extraction in a hollow-fiber membrane contactor [16], aroma compound recovery from hydro alcoholic solutions by PV coupled with fractionation (condensation) [17], and recovery of volatile aroma compounds from black currant juice by vacuum membrane distillation [18].

In practical applications, the recovery of low solubility aroma compounds from aqueous solutions by $\mathrm{PV}$ is most likely performed in a batch process due to its low processing capacities, mainly attributed to the very low concentration (ppm levels) of aroma compounds in natural sources. A dilute aqueous aroma solution is required for PV feed, and can be obtained 


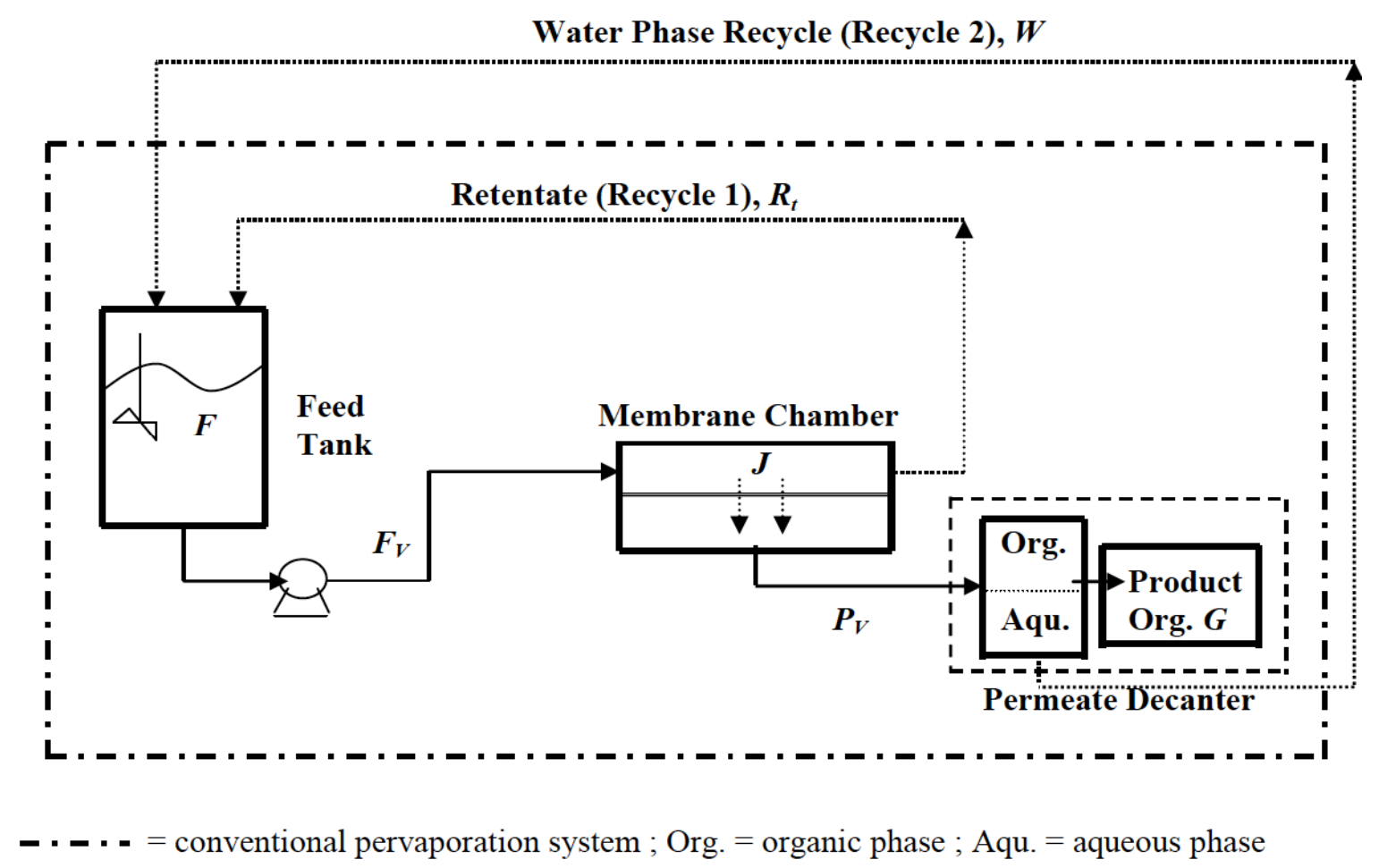

Figure 1: Batch PV of aroma compound recovery from aqueous solutions with permeate decantation and water phase recycle.

by extracting the aroma compound from the natural sources using a large amount of water. Though most industrial applications prefer continuous processes, a batch process is more suitable in the following circumstances: low processing capacity, high fouling process that needs frequent cleaning [19]. However, a batch process suffers from the disadvantage that it will never reach a steady state condition and all the process parameters will change with time.

This work aims to provide a mathematical model that can describe an operation of batch $\mathrm{PV}$ process for recovery of low solubility aroma compounds from aqueous solutions where the water phase from permeate decantation is recycled to enhance aroma recovery. The model was derived from mass balances, followed by substitutions to obtain differential or algebraic equations. From the model, the extent of improvement in the recovery of aroma compounds and other advantages due to the recycle of the water phase as compared to the conventional PV process, can be determined. The model is able to determine the process parameters as a function of time, including the permeation flux and aroma compositions in the feed tank, the quantity of permeate and retentate, and the quantity and composition of aroma produced recovered. The profiles of process parameters shown in this work are all from model simulation.

\section{MODEL DERIVATION}

Some major assumptions are considered in the derivation of model i.e. (i) isothermal operation, (ii) perfect mixing of feed solution, (iii) sorption equilibrium on the membrane surface, (iv) the permeation through the membrane follows Fick's law, and (v) the aqueous and organic phases in the permeate decanter are at equilibrium. The assumption $(v)$ is taken since PV of low aroma solubility will produce aroma permeate with an overall aroma concentration higher than its solubility.

To derive the model, the modified PV process may be divided into three sub-units: feed tank, membrane chamber, and the permeate decanter. The derivation of the mathematical model based on the overall system and partial units is as follows:

\section{Overall System}

Considering the whole modified PV system, it can be seen that a decrease in mass in the feed tank $(F)$ will equal to the increase in mass in the organic phase $(G)$ collected in the product collector,

$-d F=d G$

Since initially $(t=0)$ there is no organic phase collected in the permeate collector $\left(G_{0}=0\right)$, integration of Eqn. (1) gives, 


$$
G=F_{0}-F
$$

where $F_{0}$ is the total mass in the feed tank initially. Eqn. (2) determines the mass of aroma product collected.

\section{Feed Tank}

The total mass balance (aroma compound and water) around the feed tank can be derived as follows,

Rate of input - Rate of output $=$ Rate of accumulation

$R_{t}+W-F_{V}=\frac{d F}{d t}$

Similarly, in term of mass balance of aroma component,

$$
x_{R} R_{t}+x_{W} W-x_{F} F_{V}=\frac{d\left(x_{F} F\right)}{d t}
$$

Or,

$x_{R} R_{t}+x_{W} W-x_{F} F_{V}=x_{F} \frac{d F}{d t}+F \frac{d x_{F}}{d t}$

where $R_{t}, W$, and $F_{V}$ are the mass flow rates of the retentate, water phase recycle from the permeate decanter and the feed streams, respectively, and $x_{R}$, $x_{W}$, and $x_{F}$ are the aroma compositions (in mass fraction) in these streams, respectively. Substitution of Eqn. (3) into (5) and rearrangement gives,

$\frac{d x_{F}}{d t}=\frac{R_{t}\left(x_{R}-x_{F}\right)+W\left(x_{W}-x_{F}\right)}{F}$

Eqn. (6) expresses the composition of aroma compound in the feed tank as a function of time. The correlation between $R_{t}$ and $x_{R}$ and $W$ is obtained from the mass balance on the membrane chamber and the permeate decanter, respectively.

\section{Membrane Chamber}

The total mass balance and the aroma mass balance surrounding the membrane chamber can be derived to determine the mass flow rate and composition of retentate stream (recycle 1),

$R_{t}=F_{V}-P_{V}$

where $P_{V}$ is the mass flow rate of permeate stream leaving the membrane unit. The mass flow rate of the feed stream $\left(F_{V}\right)$ is determined by the feed circulation rate, whereas the permeation rate $\left(P_{V}\right)$ can be evaluated using the solution-diffusion model. As an approximation, $P_{V}$ can be expressed as follows,

$$
P_{V}=\sum J_{i} A_{m}=\frac{A_{m}}{l_{m}} \sum D_{i} C_{s F, i}=\frac{A_{m} \rho_{m}}{l_{m}} \sum S_{i} D_{i} x_{F, i}
$$

where $J_{i}$ is the permeation flux of permeant $i, A_{m}$ is the effective area of the membrane, $I_{m}$ is the thickness of the membrane, $D_{i}$ is the diffusivity of component $i$ through the membrane and $C_{s F, i}$ is the concentration of component $i$ on the membrane surface at the feed side. $\rho_{m}$ is the density of the membrane, $S_{i}$ is the solubility coefficient of permeant $i$ and $x_{F, i}$ is the mass fraction of permeant $i$ in the bulk feed.

Similarly, the mass balance on aroma component in the membrane chamber can be given by

$x_{R} R_{t}=x_{F} F_{V}-x_{P} P_{V}$

where $x_{P}$ is the overall composition of the aroma component in the permeate stream. The permeate composition is determined by the membrane performance, and $x_{P}$ can be related to $x_{F}$ and the enrichment factor $(\beta)$ [20].

$x_{P}=\beta x_{F}$

Substituting of Eqn. (10) into (9) and rearranging,

$x_{R}=\frac{x_{F}\left(F_{V}-\beta P_{V}\right)}{R_{t}}$

which gives the aroma component concentration in the retentate stream.

\section{Permeate Decanter}

The total and component mass balances surrounding the permeate collector are described by Eqns. (12) and (13).

$$
\begin{aligned}
& P_{V}-W=\frac{d G}{d t} \\
& \beta x_{F} P_{V}-x_{W} W=\frac{d\left(x_{G} G\right)}{d t}
\end{aligned}
$$

Or,

$$
\beta x_{F} P_{V}-x_{W} W=x_{G} \frac{d G}{d t}+G \frac{d x_{G}}{d t}
$$

The right-hand side term in Eqn. (13), i.e., $d\left(x_{G}, G\right) / d t$, basically represents the mass of aroma 
compound that is recovered at a given time. In the permeate decanter where the overall permeate concentration is beyond the aroma solubility limit, there will be an equilibrium between the organic and aqueous phases, and the aroma concentrations in the organic phase $\left(x_{G}\right)$ and water phase $\left(x_{W}\right)$ are relatively constant. Substitution of Eqn. (12) into (14) gives the mass flow rate of water phase stream (recycle 2):

$W=\frac{\left(\beta x_{F}-x_{G}\right) P_{V}}{\left(x_{W}-x_{G}\right)}$

The equations describing the PV of low solubility aroma compound recovery from aqueous solutions with two recycle streams are summarized in Table 1 . In order to compare this modified PV process to the conventional one, the mass balance equations of conventional PV are also provided in the table.

These equations can be solved numerically by means of Polymath provided that the values of $F_{V}, F_{0}$, $S, D, A_{m}, \rho_{m}, I_{m}, \beta, x_{G}$ and $x_{W}$ are all known. The changes in all the process parameters with time can be determined from the model equations; however, this study only highlights those that are considered important to compare the two modes of operation, including the mass in the feed tank and its composition, the permeation flux, the composition in the permeate stream, and the recovery of aroma compound that can be achieved. It must be noticed that the equations apply when the permeate concentration is beyond the solubility limit and phase separation occurs. If the feed aroma concentration is so low that the permeate aroma concentration is below the solubility limit, there will be no phase separation in the permeate.

\section{RESULTS AND DISCUSSION}

\section{Effect of $F_{0} / A_{m}$}

For the purpose of illustration, the model was applied to PV separation of propyl propionate-water mixtures using PEBA membrane (grade 2533) based on lab test conditions. Two parametric studies were chosen, i.e.: one was by varying the ratio of the initial feed mass over the membrane area used $\left(F_{0} / A_{m}\right)$, and the other was by varying the values of aroma solubility in water phase to see how the solubility affect the recovery. The ratio of $\left(F_{0} / A_{m}\right)$ is selected as a combined parameter instead of using $F_{0}$ or $A_{m}$ individually, because it is that will affect the aroma compound recovery. For a given $F_{0} / A_{m}$ ratio, any variations of $F_{0}$ and $A_{m}$ will not change the values of performance in term of aroma recovery. The simulation with other aroma compounds are represented by the aroma solubility of $0.5,1$, and 5 wt. $\%$. The process conditions and other parameters used in the calculations are given in Table 2.

Table 1: Model Equations for Recovery of Low Solubility Aroma Compounds from Aqueous Solutions by PV with Two and One Recycle Streams

\begin{tabular}{|c|c|c|}
\hline Two Recycles & Remarks & One Recycle \\
\hline $\begin{array}{l}\text { Eqn. (3) } \\
\text { Eqn. (6) }\end{array}$ & $\begin{array}{l}\text { - to determine the mass in the feed tank as a function of time } \\
\text { - to determine the concentration of aroma in the feed tank as a function of } \\
\text { time }\end{array}$ & $\begin{array}{c}\frac{d F}{d t}=R_{t}-F_{V} \\
\frac{d x_{F}}{d t}=\frac{R_{t}\left(x_{R}-x_{F}\right)}{F}\end{array}$ \\
\hline $\begin{array}{l}\text { Eqn. (8) } \\
\text { Eqn. (10) }\end{array}$ & $\begin{array}{l}\text { - to determine the mass flow rate of the permeate stream as a function of } \\
\text { time } \\
\text { - to determine the concentration of aroma in the permeate stream as a } \\
\text { function of time }\end{array}$ & Same \\
\hline $\begin{array}{l}\text { Eqn. (7) } \\
\text { Eqn. (11) }\end{array}$ & $\begin{array}{l}\text { - to determine the mass flow rate of retentate stream as a function of time } \\
\text { - to determine the concentration of aroma in the retentate stream as a } \\
\text { function of time }\end{array}$ & Same \\
\hline Eqn. (15) & $\begin{array}{l}\text { - to determine the mass flow rate (or mass collected) of water phase in } \\
\text { decanter as a function of time }\end{array}$ & $\frac{d W}{d t}=\frac{\left(\beta x_{F}-x_{G}\right) P_{V}}{\left(x_{W}-x_{G}\right)}$ \\
\hline $\begin{array}{l}\text { Eqn. (2) or } \\
\qquad(12) \\
\text { Eqn. (13) }\end{array}$ & - to determine the mass of aroma compound recovered as a function of time & $\begin{array}{l}\frac{d G}{d t}=\frac{\left(\beta x_{F}-x_{W}\right) P_{V}}{\left(x_{G}-x_{W}\right)} \\
\text { or } G=F-F_{0}-W \\
M_{\text {org, re covered }}=x_{G} G\end{array}$ \\
\hline
\end{tabular}


Table 2: Process Conditions and other Parameters Used in Model Calculation for Propyl Propionate-Water Recovery

\begin{tabular}{|c|c|}
\hline Parameter & Quantity \\
\hline $\begin{array}{l}\text { - Initial mass of feed per membrane area, } F_{o} / A_{m} \\
\text { - Initial feed concentration } \\
\text { - Solubility of propyl propionate in water phase } \\
\text { - Feed circulation, } F_{V} \\
\text { - Solubility coefficient of propyl propionate in PEBA membrane, } S_{i} \\
\text { - Solubility coefficient of water in PEBA membrane as a function of mass fraction of propyl } \\
\text { propionate } \\
\text { - Diffusivity of propyl propionate in PEBA membrane (from PV experiment data, average value), } \\
D_{i} \\
\text { - Diffusivity of water in PEBA membrane (from PV experiment data, average value) } \\
\text { - Enrichment factor (average value), } \beta \\
\text { - Thickness of membrane, } I_{m} \\
\text { - Solubility of water in propyl propionate phase } \\
\text { - Density of PEBA membrane, } \rho_{m}\end{array}$ & $\begin{array}{l}375,150,15 \mathrm{~kg} / \mathrm{m}^{2} \\
1,000 \mathrm{ppm} \\
5,600 \mathrm{ppm}(0.56 \mathrm{wt} . \%)[21] \\
1.6 \mathrm{~kg} / \mathrm{min} \\
4.6014 \mathrm{~g} /(\mathrm{g} \text { membrane.ppm) } \\
1.784 X_{p p}+0.0078, \mathrm{~g} \text { water } / \mathrm{g} \text { membrane } \\
6.5 \times 10^{-11} \mathrm{~m}^{2} / \mathrm{s} \\
1.4 \times 10^{-10} \mathrm{~m}^{2} / \mathrm{s} \\
185 \\
25 \mu \mathrm{m} \\
1 \mathrm{wt.} \%[22] \\
1.010 \mathrm{~kg} / \mathrm{m}^{3}[23]\end{array}$ \\
\hline
\end{tabular}

$X_{p p}=$ mass fraction of propyl propionate in the feed solution

All transport properties are evaluated at $25-30^{\circ} \mathrm{C}$.

The diffusivity and enrichment factor were obtained from processing data of our PV experiments, which were the average values at various feed concentrations investigated, after the solubility coefficient was determined from sorption experiments.

The diffusivity and enrichment factor were obtained from processing data of our PV experiments, which were the average values at various feed concentrations investigated, after the solubility coefficient was determined from sorption experiments.

Figure 2 shows the profiles of mass in the feed tank and its composition during $50 \mathrm{~h}$ of operation with and without water phase recycle from the permeate decanter at various $\left(F_{0} / A_{m}\right)$ values. A wide range of operating time was used in order to get comprehensive description about the process parameters that will be evaluated. Clearly, the mass in the feed tank decreases with time increases since a product stream (i.e., organic phase, $G$ ) is continuously withdrawn from

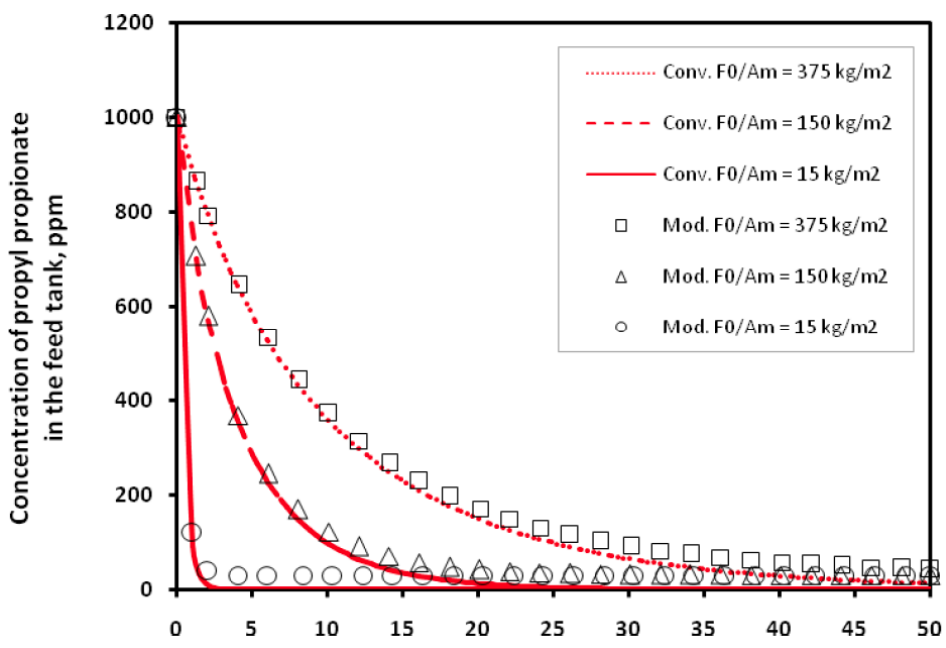

the system. However, the two modes of operation have a different trend. The water phase recycle changes the mass in the feed tank only slightly for all the $\left(F_{0} / A_{m}\right)$ values studied $\left(15-375 \mathrm{~kg} / \mathrm{m}^{2}\right)$. It may be mentioned that the variation of $\left(F_{0} / A_{m}\right)$ has little effect on the mass change in the feed tank when the permeate stream is dominated by the water phase; in this case, most permeate stream will be recycled again into the feed tank.

The dominant phase in the permeate stream can be seen from the overall permeate concentration, which will be shown later. In the conventional operation, however, there is a clear decrease in mass in the feed tank during the operation, and the extent of decrease

Figure 2: Profiles of mass in the feed tank and its composition as a function of time. 
depends on the ratio of $\left(F_{0} / A_{m}\right)$ used. A lower $\left(F_{0} / A_{m}\right)$, which means a larger membrane area for a given amount of feed, can augment the decrease in the mass of the feed solution. It is reasonable since a larger membrane area gives a higher permeation rate and no permeate is recycled to the system in the conventional mode of operation. In $50 \mathrm{~h}$ the mass in the feed tank for the modified PV system decreases by only $0.1 \%$, whereas in the conventional PV system its decrease reaches $2.4 \%$ for $F_{0} / A_{m}=375 \mathrm{~kg} / \mathrm{m}^{2}$ up to $53.2 \%$ for $F_{0} / A_{m}=15 \mathrm{~kg} / \mathrm{m}^{2}$.

For the feed composition, however, the two modes of operation show similar trends. In general, the concentration of propyl propionate decreases sharply in the early period and the decrease becomes gradually slower as PV proceeds. During the operation, the feed concentration in the modified PV system is found slightly higher than that in the conventional operation. This makes sense since the water phase recycled still contains a small amount of propyl propionate. It is clear the decrease in feed propyl propionate concentration for both modes of operation is significant. This further justifies that PEBA membrane can concentrate the aroma compounds from aqueous solutions by PV.

It can be concluded that all propyl propionate in the feed stream can be completely taken out through membrane permeation in the conventional PV system; however, some of this amount will be trapped in the water phase in the permeate collector. In contrast, the feed propyl propionate concentration in the modified PV system will decrease with time more slowly because the water phase recycle supplies propyl propionate into the feed stream. The utilization of a larger membrane area (or lower $\left(F_{0} / A_{m}\right)$ ) essentially shortens the operating time required. To achieve zero feed concentration, $\left(F_{0} / A_{m}=375 \mathrm{~kg} / \mathrm{m}^{2}\right)$ operates up to around $50 \mathrm{~h}$, whereas $\left(F_{0} / A_{m}=150 \mathrm{~kg} / \mathrm{m}^{2}\right)$ and $\left(F_{0} / A_{m}=\right.$ $15 \mathrm{~kg} / \mathrm{m}^{2}$ ) just take around 30 and $4 \mathrm{~h}$, respectively.

The very similar profile between the two modes of operation is also found in permeation flux, with a little bit different in permeate compositions, as shown in Figure 3. For both systems, it can be seen that the permeation flux decreases sharply in the early stages, then becomes slower and finally reaches nearly constant (asymptotic curve). This is reasonable since the permeation flux is affected directly by the feed propyl propionate concentration.

The overall concentration of propyl propionate in the permeate stream obtained by PV separation depends on the membrane performance. For a constant enrichment factor, the concentration of propyl propionate in the permeate stream also decreases asymptotically because of the decrease in the feed propyl propionate concentration. For the permeate concentrations, it can be seen that the permeate stream is still dominated by water even at the highest propyl propionate concentration (i.e., 18.5 wt.\%). Therefore, by recycling the water phase, the mass in the feed tank changes very slightly as shown in Figure 2.

It must be noticed that the application of water phase recycle is only meaningful when the concentration of propyl propionate in the permeate stream exceeds its solubility limit. Once the instantaneous permeate concentration at a certain moment is exactly the same as its solubility limit, the process must stop. Otherwise, there is no phase
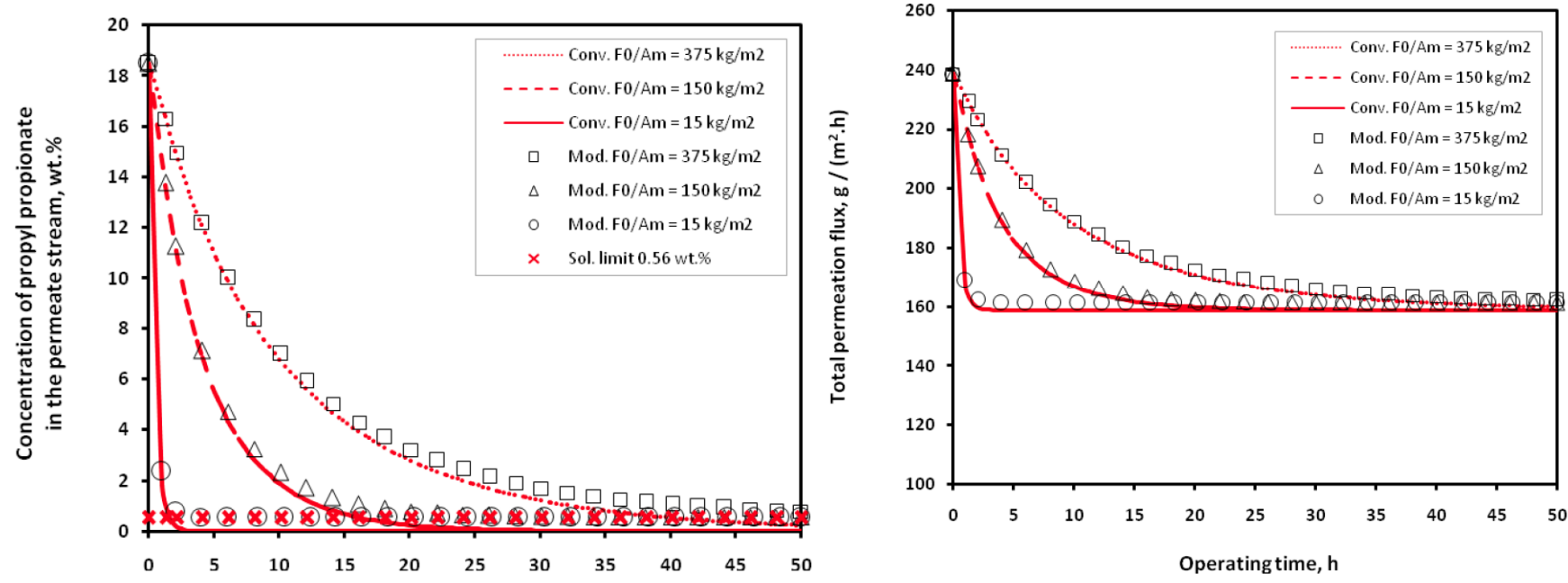

Figure 3: Profiles of total permeation flux and the composition in the permeate stream as a function of time. 

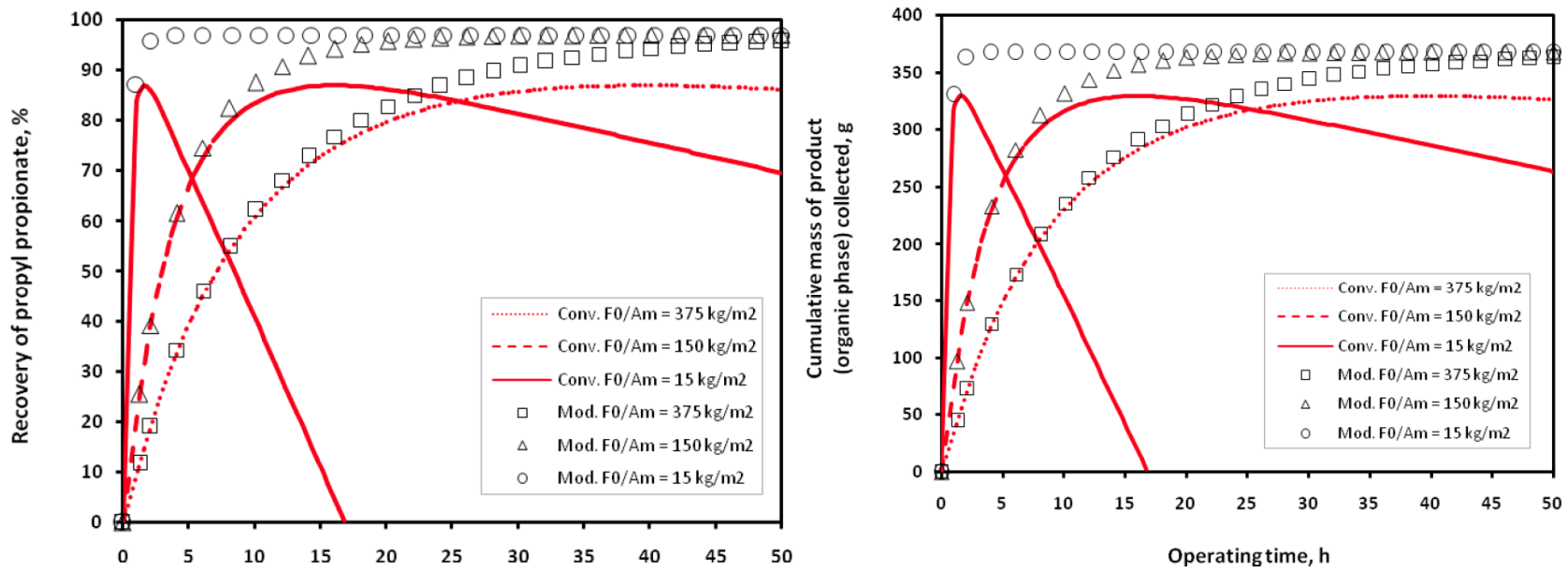

Figure 4: Mass of product (organic phase) collected and recovery of propyl propionate as a function of time.

separation in the newly collected permeate any more, and it is a homogeneous mixture.

Figure $\mathbf{4}$ shows the cumulative mass of product (i.e., organic phase) collected in the permeate decanter and the propyl propionate recovery obtained as a function of time. The two figures are similar but not identical since the organic phase is still filled by a very small amount of water. The recovery is defined as the ratio of the cumulative mass of propyl propionate collected in the organic phase to the initial amount of propyl propionate in the feed tank. The two modes of operation show very similar performance in the early period of permeation. As PV proceeds, PV with two stream recycles shows better performance. As expected, the water phase recycle can improve the recovery of propyl propionate to some extent depending on the operating time set. In the modified PV system, the mass of organic phase and propyl propionate recovered increases continuously and this is not the case for the conventional PV system. In the conventional system, there is an optimum operating time at which a maximum recovery can be obtained. This corresponds to the moment at which the instantaneous permeate concentration reaches the solubility limit. Initially, the mass of propyl propionate recovered increases gradually and then decreases continuously afterward. For this reason, due to the water phase recycle, a longer operating time can be used to improve the propyl propionate recovery.

The existence of optimum operating time in the conventional PV system can be explained from the equilibrium phase concept: in the permeate collector the water phase and organic phase are in contact. Because the concentration of propyl propionate in the permeate stream decreases as the operating time increases (Figure 3), the water accumulated in the permeate collector will be more dominant than propyl propionate. There will be mass transfer between the two phases to reach phase equilibrium. The domination of water in the permeate collector attracts propyl propionate from the organic phase to enter the water phase to attain the equilibrium. The migration of propyl propionate causes the mass of propyl propionate in the organic phase decrease with time. At a certain time, the amount of water in the decanter can be large enough that there will be no phase separation, and the decanter only contains the water phase. In addition, the condition when the optimum operating time occurs in the conventional PV system can also be analyzed mathematically. The maximum mass of propyl propionate in organic phase collected is obtained when $\frac{d G}{d t}=0$. Since during the process the permeation rate $\left(P_{V}\right)$ is not zero, this means $\left(\beta x_{F}-x_{W}\right)=0$. In other words, the optimum operating time is reached when the concentration of propyl propionate in the permeate stream at a given moment $\left(x_{P}\right.$ or $\left.\beta x_{F}\right)$ is the same as its solubility limit $\left(x_{W}\right)$. It is clear that the process must be stopped at this point. In the modified PV system, however, the cumulative mass of propyl propionate recovered is found relatively unchanged (with little increase in propyl propionate recovery) when the permeate stream composition approaches to the solubility limit. It is more efficient to operate the modified PV system before the concentration of propyl propionate in the permeate streams reaches its solubility limit, as shown in Figure 4.

Interestingly, it can be mentioned that the utilization of larger membrane area does not affect the maximum recovery of propyl propionate that can be achieved; only the time to obtain the maximum recovery becomes shorter. In the conventional PV system, the maximum recovery is $87.0 \%$, which is achieved at optimum operating times of 40,16 and $1.5 \mathrm{~h}$ for $\left(F_{0} / A_{m}=375\right.$ $\left.\mathrm{kg} / \mathrm{m}^{2}\right),\left(F_{0} / A_{m}=150 \mathrm{~kg} / \mathrm{m}^{2}\right)$ and $\left(F_{0} / A_{m}=15 \mathrm{~kg} / \mathrm{m}^{2}\right)$, 
respectively, while the modified $\mathrm{PV}$ system has a recovery of over $94.0 \%$ recovery.

\section{Effect of Aroma Solubility in Water on Aroma Recovery}

The simulation was also performed by varying the aroma solubility in the water phase. Not all the process parameters given in the above simulation are discussed; only the comparison in the recovery will be presented. Figure $\mathbf{5}$ shows the effects of aroma solubility in water (in the range of $0.56-5 \mathrm{wt} . \%$ ) on the aroma compound recovery.

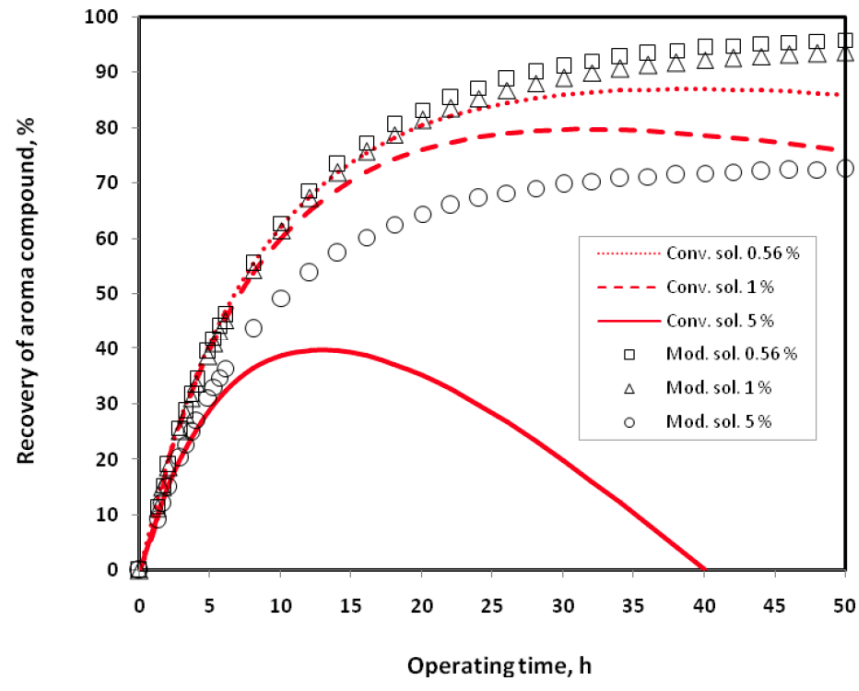

sol. $=$ aroma solubility in water (in wt.\%)

Figure 5: Recovery of aroma compound as a function of time at various aroma solubility in water $\left(F_{0} / A_{m}=375 \mathrm{~kg} / \mathrm{m}^{2}\right)$.

It can be seen that the two modes of operation show very distinctive performance when the addition of water phase recycle is applied, especially for higher aroma compound solubility. This makes sense that the higher solubility of aroma compound in water means more aroma compound exists in the water phase, and thus water phase recycling becomes more indispensable. For the solubility of aroma compound of $0.56,1$, and $5 \mathrm{wt} . \%$, at the optimum operating time in the conventional PV system (which are 40,32 , and 13 $h$, respectively) as a benchmark, the use of water phase recycle can improve the recovery of aroma compound from 87.0 to $94.0 \%$, from 80.0 to $90.0 \%$ and from to 40.0 to $56.0 \%$, respectively. The recovery can be higher if the modified PV system is run for a little longer period of time.

Note that a higher solubility of aroma compound in water can reduce the recovery of aroma compound that can be achieved for both systems. This is especially important when dealing with the selection of operating temperature. Generally speaking, a higher operating temperature increases the permeation flux and thus more aroma compound can be collected; however, the solubility of aroma compound in the water phase will increase as well, and thus reduce the recovery of aroma compound. In this sense, it is expected that there will also be an optimum operating temperature in obtaining the maximum recovery of aroma compounds from aqueous solutions.

\section{CONCLUSIONS}

The recovery of low soluble aroma compounds from aqueous solutions by a modified PV process, which was a conventional PV process coupled with permeate decantation and water phase recycle, was simulated with two parametric models (i.e., ratio of feed mass over membrane area $\left(F_{0} / A_{m}\right)$ and the solubility of aroma compound in water). The simulation showed that as compared to the conventional PV process, the application of water phase recycle was able to enhance the recovery of aroma compounds in various extents, depending on the operating time and aroma solubility. At a given $\left(F_{0} / A_{m}\right)$, the longer operating time increased the improvement in aroma compound recovery. However, the utilization of a larger membrane area (or smaller $\left.\left(F_{0} / A_{m}\right)\right)$ did not affect the maximum aroma recovery that can be achieved, but only shortened the operating time. The higher the solubility of aroma compound in the water is, the application of water phase recycle is strongly recommended due to its significant improvement in recovery. Another advantage offered by the modified PV system was that practically there was no strict restriction dealing with the operating time to obtain as much as aroma recovery where the conventional PV system must be care of it. In the modified PV system, the aroma compound recovered in the product increased permanently; whereas, there was an optimum operating time to obtain the maximum recovery in the conventional PV system. In order to attain maximum recovery, the conventional operation must be stopped when the permeate concentration reaches solubility limit. It may be mentioned that the mathematical model in Eqn. (1) to (15) can also be applied for different operating temperatures, using the physical properties (diffusivity, solubility) evaluated at corresponding temperature.

\section{ACKNOWLEDGEMENTS}

We would convey much gratitude to the Sciences and Engineering Research Council (NSERC) of 
Canada for the research support in conducting the experimental part of this work. One of the authors (MM) would also thank to the Technological and Professional Skills Development Sector (TPSD) Project and the Universitas Muhammadiyah Surakarta (UMS) Indonesia for funding the project.

\section{NOMENCLATURE}

$$
\begin{aligned}
& A_{m} \quad=\text { cross area of membrane, } \mathrm{m}^{2} \\
& D_{i} \quad=\begin{array}{l}
\text { diffusivity coefficient of component } i, \\
\mathrm{~m}^{2} / \mathrm{h}
\end{array}
\end{aligned}
$$

$F, F_{0} \quad=$ mass of the mixture in the feed tank at any time, initial, $g$

$F_{V} \quad=$ mass flow rate of feed stream, $\mathrm{g} / \mathrm{h}$

$J=$ total permeation flux through the membrane, $g /\left(m^{2} . h\right)$

$I_{m} \quad=$ membrane thickness, $\mathrm{m}$

$P \quad=$ mass of organic phase collected in the permeate collector, $g$

$P_{V} \quad=$ mass flow rate of permeate stream, $\mathrm{g} / \mathrm{h}$

$R=$ mass flow rate of retentate stream, $\mathrm{g} / \mathrm{h}$

$S_{i} \quad=$ solubility coefficient of component $i$

$t=$ operating time, $\mathrm{h}$

$W \quad=$ mass flow rate (or mass) of water phase stream (or water phase), g/h, g

$X_{F}, X_{G}, X_{P}=$ mass faction of aroma compound in the feed tank, organic phase, permeate stream

$x_{R}, x_{W}=$ mass fraction of aroma compound in the retentate stream, water phase stream

$\beta=$ enrichment factor

$\rho_{m} \quad=$ density of membrane, $\mathrm{g} / \mathrm{m}^{3}$

\section{REFERENCES}

[1] Baker RW. Membrane Technology and Applications, $2^{\text {nd }}$ ed.; John Wiley \& Sons, Ltd.; West Sussex, USA 2004. https://doi.org/10.1002/0470020393

[2] Le NL, Wang Y, Chung TS. Pebax/POSS mixed matrix membranes for ethanol recovery from aqueous solutions via pervaporation. J Membr Sci 2011; 174: 55-65. https://doi.org/10.1016/i.memsci.2011.05.060
Chen MSK, Eng RM, Glazer JL, Wensley CG. Pervaporation process for separating alcohols from ethers, US Patent 1988; $4,774,365$.

[4] Chen MSK, Markiewicz GS, Venugopal KG. Development of membrane pervaporation TRIM $^{\mathrm{TM}}$ process for methanol recovery from $\mathrm{CH} 3 \mathrm{OH} / \mathrm{MTBE} / \mathrm{C} 4$ mixtures, in Membrane Separations in Chemical Engineering, AICHE Symposium Series, Number 272, A.E. Fouda, J.D. Hazlett, T. Matsuura, and J. Johnson (eds), AICHE, New York, NY, 1989; p. 85. Huang RYM. Separation of aroma compounds from aqueous solutions by pervaporation using polyoctylmethyl siloxane (POMS) and polydimethyl siloxane (PDMS) membranes. J Membr Sci 2000; 174: 55-65. https://doi.org/10.1016/S0376-7388(00)00365-3

[6] Baudot A, Marin M. Dairy aroma compounds recovery by pervaporation. J Membr Sci 1996; 120: 207-220. https://doi.org/10.1016/0376-7388(96)00144-5

[7] Schafer T, Bengtson G, Pingel H, Boddeker KW, Crespo JPSG. Recovery of aroma compounds from a wine-must fermentation by organophilic pervaporation. Biotechnol and Bioeng 1999; 62: 412-421.

https://doi.org/10.1002/(SICl)1097 0290(19990220)62:4<412::AID-BIT4>3.0.CO;2-R

Tian X, Zhu B, Xu Y. P(VDF-co-HFP) membrane for recovery of aroma compounds from aqueous solutions by pervaporation I. Ethyl acetate/water system. J Membr Sci 2005; 248: 109-117. https://doi.org/10.1016/j.memsci.2004.10.003

[9] Rajagopalan N, Cheryan M. Pervaporation of grape juice aroma. J Membr Sci 1995; 104: 243-250. https://doi.org/10.1016/0376-7388(95)00039-F

[10] Borjesson J, Karlsson HOE, Tragardh G. Pervaporation of a model apple juice aroma solution: comparison of membrane performance. J Membr Sci 1996; 119: 229-239. https://doi.org/10.1016/0376-7388(96)00123-8

[11] Pereira CC, Rufino JRM, Habert AC, Nobrega R, Cabral LMC, Borges CP. Aroma compounds recovery of tropical fruit juice by pervaporation: membrane material selection and process evaluation. J Food Eng 2005; 66: 77-87. https://doi.org/10.1016/j.jfoodeng.2004.02.037

Karlsson HOE, Loureiro S, Tragardh G. Aroma compound recovery with pervaporation - Temperature effects during pervaporation of a muscat wine. J Food Eng 1995; 26: 177191. https://doi.org/10.1016/0260-8774(94)00050-J

[13] Olsson J, Tragardh G. Infuence of feed flow velocity on pervaporative aroma recovery from a model solution of apple juice aroma compounds. J Food Eng 1999; 39: 107-115. https://doi.org/10.1016/S0260-8774(98)00154-X

[14] Baudot A, Souchon I, Marin M. Total permeate pressure infuence on the selectivity of the pervaporation of aroma compounds. J Membr Sci 1999; 158: 167-185. https://doi.org/10.1016/S0376-7388(99)00018-6

[15] Liu K, Tong Z, Liu L, Feng X. Separation of organic compounds from water by pervaporation in the production of n-butyl acetate via esterification by reactive distillation. $J$ Membr Sci 2005; 256: 193-201. https://doi.org/10.1016/j.memsci.2005.02.020

[16] Younas M, Bocquet SD, Sanchez J. Extraction of aroma compounds in a HFMC: Dynamic modelling and simulation. J Membr Sci 2008; 323(2): 386-394. https://doi.org/10.1016/j.memsci.2008.06.045

[17] Brazinha C, Crespo JG. Aroma recovery from hydro alcoholic solutions by organophilic pervaporation: Modelling of fractionation by condensation. J Membr Sci 2009; 341(1-2): 109-121. https://doi.org/10.1016/j.memsci.2009.05.045 
[18] Soni V, Abildskov J, Jonsson G, Gano R. Modeling and analysis of vacuum membrane distillation for the recovery of volatile aroma compounds from black currant juice. J Membr Sci 2008; 320(1-2): 442-455.

https://doi.org/10.1016/j.memsci.2008.04.025

[19] Walas SM. Chemical process equipment: selection and design; Butterworths; Boston, USA 1988.

[20] Huang RYM, Ed. Pervaporation membrane separation processes; Elsevier; New York, USA 1991.

[21] Perry RH, Green DW. Perry's Chemical Engineers' Handbook, $7^{\text {th }}$ ed.; McGraw-Hill Book Companies, Inc., New York, USA 1999
[22] Stephenson R, Stuart J. Mutual binary solubilities: wateralcohols and water-esters. J Chem Eng Data 1986; 31: 5670.

https://doi.org/10.1021/je00043a019

[23] Djebbar MK, Nguyen QT, Clement R, Germain $Y$. Pervaporation of aqueous ester solutions through hydrophobic poly(ether-block-amide) copolymer membranes. J Membr Sci 1998; 146: 125-133.

https://doi.org/10.1016/S0376-7388(98)00090-8 